mean error of not more than $\pm 0.15 \mathrm{~km} / \mathrm{sec}$ for one plate. An accuracy of this sort would make it possible to obtain new and powerful material bearing on the solution of a number of astronomical problems.

\title{
REFERENCES
}

I. Jones, H. S., Furner, H. H. Mon. Not. R. astr. Soc., 98, 92, 1937.

2. Adams, W. S. Astrophys. F., 93, II, 1941.

3. Evans, D. S. R. Obs. Bull. no. $77,1963$.

\section{SPECTROSCOPIC OBSERVATIONS OF SCO-CEN STARS}

\section{A. D. Thackeray}

During the past two seasons considerable effort has been made at the Radcliffe Observatory to observe radial velocities of members of the Sco-Cen association. As a result of this Radcliffe velocities are now available for over 100 Sco-Cen stars-about three times as many as have been included in published work.

The Radcliffe system of velocities agrees well with the GCRV system, as judged by the observations of IAU standard velocity stars of late type. Twenty observations of standard stars during these seasons give the mean difference Radcliffe - GCRV $=-0.16 \pm 0.5 \mathrm{~km} / \mathrm{sec}$. There appears to be a tendency for Radcliffe velocities of the bright Sco-Cen stars to run more negative than Lick by about $2 \mathrm{~km} / \mathrm{sec}$, but this is quite inadequate to give rise to doubts about a large $K$-term for the association. The tendency appears to be especially large between $9^{\mathrm{h}}$ and $13^{\text {h }}$ R.A. and extension of the system to longitudes less than $l^{\mathrm{I}}=264$ is quite doubtful.

Forty-two stars in the central region with Radcliffe observations have mean velocities which show a mean square residual of $3.8 \mathrm{~km} / \mathrm{sec}$ from Bertiau's solution I; this is a reduction of $3 \circ$ per cent (from $5.5 \mathrm{~km} / \mathrm{sec}$ ) compared with the residuals of the velocities actually used by Bertiau for the same 42 stars.

While an important part of the programme has been directed at improving the accuracy of already known velocities, a second part has been concerned with measuring radial velocities of faint components of visual binaries which have never been observed before with slit spectrograph. This had two objectives:

(r) To test whether the radial velocities of components of type A and later show the same positive $K$-term as is well known among the B-type members.

(2) To investigate the spectral types of these fainter stars as a clue to the evolution of a 'young system'.

Some 20 visual pairs have been investigated and velocities measured for 14; among these 14, velocities appear to be variable for six primaries and, less certainly, for seven secondaries. For the six best observed pairs, we find for the mean difference

$$
V_{S}-V_{\mathrm{p}}=-{ }_{\mathrm{I}} \cdot 6 \pm \mathrm{I} \cdot 9 \mathrm{~km} / \mathrm{sec}
$$

Thus the $K$-term is not significantly different for these six secondaries of later type. Further, as proof that these particular binaries form a fair sample of members of the group, we have

$$
V_{S}-V_{B l}=-2 \cdot 3 \pm \mathrm{I} \cdot 6 \mathrm{~km} / \mathrm{sec}
$$

where $V_{B l}$ is the velocity predicted by Blaauw from his solution for the whole group. Thus there appears to be no hope of explaining the well-known $K$-term of about $+10 \mathrm{~km} / \mathrm{sec}$ in terms of some peculiar effects in the atmospheres of B type stars.

I consider that the $K$-term of the Sco-Cen stars must be regarded as a real kinematic effect. 
A preliminary analysis has been carried out for what appear to be the best available velocities in the two central groups $\left(l^{\mathrm{I}}=264\right.$ to 290 and 293 to 328$)$. No new analysis of the convergent has been attempted but two extreme convergents have been compared. Velocity residuals from Petrie's solution III are plotted against distance for the two groups. For the following group there is a very small positive correlation $+\cdot 3 \mathrm{I} \pm \cdot{ } 5$. There are, of course, very great uncertainties in both co-ordinates. The whole group is so shallow that if expansion is present it probably amounts to a total range of not more than $3 \mathrm{~km} / \mathrm{sec}$ between front and back and errors of distances will easily mask any correlation even if the velocities are known well enough.

The fact that the new observations tend to reduce the residuals compared with Bertiau's (or others') solution is important in that it strengthens the belief that the stars form a physical group; the dispersion in radial velocities is considerably less than that of B stars in the general field, quite apart from the distinctive grouping in the sky.

\section{Discussion}

Blaauw remarked that he thought the $K$-term in the Scorpio-Centaurus group was real and that there must be an expansion velocity of the order of $10 \mathrm{~km} / \mathrm{sec}$.

OBSERVATIONS AVEC LE PRISME OBJECTIF

\section{Ch. Fehrenbach}

L'Observatoire de Marseille est engagé dans son programme de mesures de vitesses radiales au Prisme Objectif avec trois instruments dont deux installés à l'Observatoire de Haute-Provence et un en Afrique du Sud (E.S.O.). Ces instruments sont décrits dans le rapport initial.

Une liste de tous les champs publiés ou mesurés ou observés sera donné rapidement au Fournal des Observateurs. Notre programme comprend plus de roo champs de petite latitude galactique (magnitude limite $9 \cdot 5$ (PPO), I I $^{\circ}$, et quelquefois I2.5 (GPO)), un certain nombre de champs à haute latitude galactique, notamment au pôle galactique nord.

Enfin un important programme sur les Nuages de Magellan permet de signaler 230 étoiles membres ou membres très probables du Grande Nuage. La liste de ces étoiles est distribuée; elle sera publiée très rapidement. Cette liste comprend un certain nombre d'étoiles de type $\mathrm{G}$ à $\mathrm{K}$ dont certaines figurent dans le $\mathrm{HDE}$ et même dans le HD (Résultats de $\mathrm{Ch}$. Fehrenbach et de Mme Duflot). Enfin Florsch (Strasbourg) a détecté 30 à 40 étoiles membres probables du Petit Nuage de Magellan; son travail est moins avancé. De nombreux clichés dans la région entre les deux Nuages sont déjà pris mais n'ont pas encore été examinés.

Dans tous cas où nous publions les vitesses radiales nous ajoutons une détermination de la classe spectrale dans le système M.K. Dans de nombreux cas des mesures $U, B, V$, ont été faites par Bigay, Bouigue et Boulon. Enfin dans plusieurs champs des mesures des intensités des raies $\mathrm{H}_{\gamma}$ et $\mathrm{H} \delta$ permettent à Mlle Martin de déterminer $M_{\mathrm{v}}$ et, à l'aide des mesures $U, B, V$, les distances.

Les mesures de vitesses radiales au Prisme Objectif ont fait l'objet de plusieurs travaux de Boulon, de Mlle Martin, et de Bonneau, qui montrent que ces mesures sont en bon accord avec celles obtenues avec le spectrographe à fente.

Notre groupe a aussi trouvé quelques étoiles à grande vitesse interessantes, dont une est le membre le plus brillant de l'amas globulaire $\omega$ Cen. Son type spectral A8 est très remarquable pour une étoile d'un amas globulaire.

L'Observatoire de Toulouse (Bouigue) vient de mettre en service un prisme objectif à champ normal de $25 \mathrm{~cm}$ de diamètre; il permettra d'atteindre la magnitude 10.5 . 


\section{THE CONSTANTS OF GALACTIC ROTATION}

\section{F. Boulon}

From observations in Io fields between galactic longitudes (new system) between $55^{\circ}$ and $192^{\circ}$ using data for stars at less than 500 pc new values of galactic constants have been derived. A total of 415 stars is involved, of which 235 are of types $B$ and $A$, and 180 of types $F, G$, and K. The speed of the Sun in the galactic plane relative to these stars $\left(v \cos b^{\mathrm{II}}\right)$ was found to be:

$$
\begin{array}{ll}
\text { B-A stars: } l^{\Pi \mathrm{I}} & =53^{\circ} .5, v \cos b^{\mathrm{II}}=20.0 \mathrm{~km} / \mathrm{sec} \\
\mathrm{F}, \mathrm{G}, \mathrm{K} & =53^{\circ} .7
\end{array}
$$

Previously accepted values for the standard solar motion are $56^{\circ}$ and $18.5 \mathrm{~km} / \mathrm{sec}$. It is assumed that there is no $K$-term, and a good accordance is then found. If a $K$-term is assumed it is found to have the large value of about $7 \cdot 1 \mathrm{~km} / \mathrm{sec}$, but this value is of purely mathematical origin and arises from the way in which the fields are distributed.

From a study of $6 \mathrm{r}$ super-giant B-stars lying between 1000 and $3000 \mathrm{pc}$ in longitudes (new system) between $117^{\circ}$ and $130^{\circ}$, the values $A=17.0 \pm 1.7 \mathrm{~km} / \mathrm{sec} / \mathrm{kpsc}$ and $K=+1 \cdot 2 \pm$ $3.4 \mathrm{~km} / \mathrm{sec}$ are derived. By another method of analysis using individual velocities the values $A=$ $15.7 \mathrm{~km} / \mathrm{sec}$ and $K=-0.6 \mathrm{~km} / \mathrm{sec}$ were derived.

\section{NEW VALUES OF $A$ AND $K$ FROM RADIAL VELOCITIES OF B-STARS AND OF INTERSTELLAR Ca ${ }^{+}$}

\section{R. M. Petrie}

This report is published in extenso in Report of Commission 33.

\section{THE MOTIONS OF SUB-DWARFS AND THE VELOCITY OF ESCAPE FROM} THE GALAXY

\section{S. Evans}

The work reported will be published jointly with M. E. Dixon and P. A. Fairall. About I6o stars within roughly 200 pc can be identified in the literature and from our own unpublished sources as sub-dwarfs. Limiting the discussion to those for which radial velocities, photometry and proper motions are available, reduces the number to about half. These are divided into groups according to observed colour and ultra-violet excess, and the motions are analysed, and absolute magnitudes determined. For example, a well-marked group of high excess sub-dwarfs, 34 in number, is found near mean $B-V=0.45$ with mean $U-B=-0.20$. These are found to have a mean absolute magnitude $M_{\mathrm{v}}=4.30$ with a systematic motion relative to the Sun mainly in the $v$-direction of about $210 \mathrm{~km} / \mathrm{sec}$. They define a velocity ellipsoid pointing towards the galactic centre with dispersions in $u, v, w$ near $170 \mathrm{~km} / \mathrm{sec}, 110 \mathrm{~km} / \mathrm{sec}$ and $90 \mathrm{~km} / \mathrm{sec}$. The other groups are naturally less well defined and are more arbitrarily limited. Similar values are obtained for high excess stars, smaller values of solar motion and dispersion for sub-dwarfs of lower excess. The known later type sub-dwarfs are not a satisfactory statistical sample, and cannot be treated in this way. For some of these last named stars the values of trigonometrical parallax can be used for the computation of space motions. The values of absolute magnitude inferred for the earlier groups show a satisfactory accordance with blanketing theory. There are altogether 84 stars for which space motions can be computed, and these can be used to estimate the escape velocity from the Galaxy from the position of the velocity cut-off shown on histograms 
of total velocity relative to a point at the solar distance which is not participating in galactic rotation. The construction of these histograms requires an assumption of the value of the circular velocity at the solar distance. However, the results turn out to be quite insensitive to the assumption made in the range from 220 to $280 \mathrm{~km} / \mathrm{sec}$. The cut off occurs at $380 \mathrm{~km} / \mathrm{sec}$ which is taken to be the velocity of escape from the Galaxy. This agrees with a new model by Maarten Schmidt. 